PLASTIC RESTORATION OF UPPER LID AND SOCKET*

BY

\author{
JAN LUC \\ (MAJOR, POLISH A.M.C.)
}

IN the June (1944) number of the Brit Jl. of Ophthal., the Editor emphasises the need to train eye surgeons in the principles of plastic surgery.

The necessity of such training seems to be all the greater for a military eye surgeon who, under war conditions, is very often unable to get in touch with a plastic surgery centre or has to wait for many

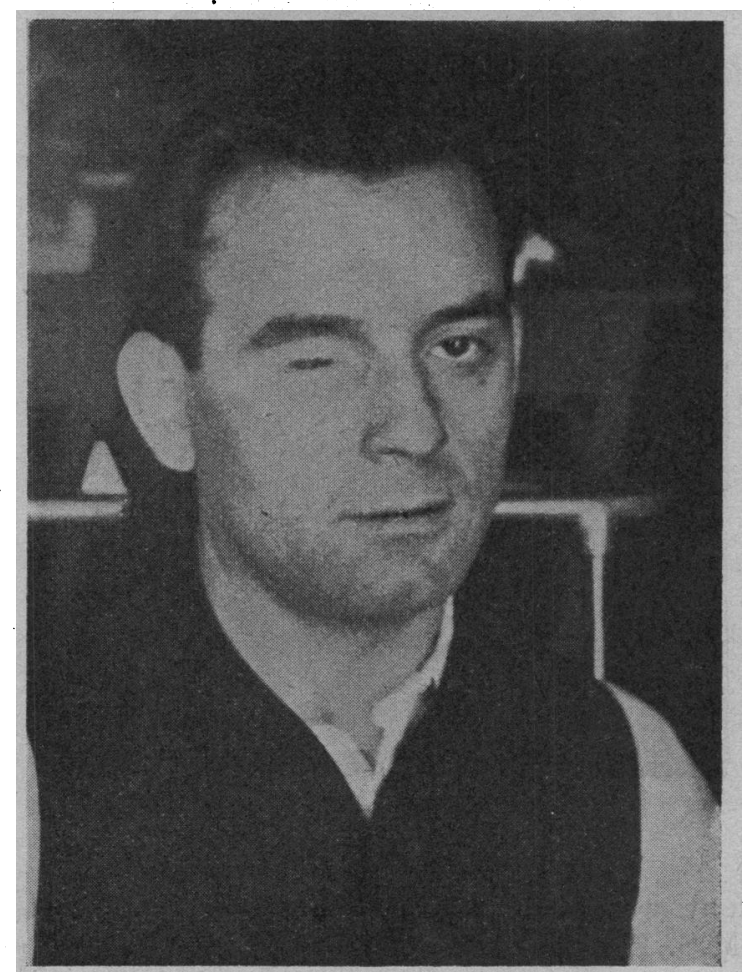

Fig. 1.

weeks before his patient can be admitted, the centre being overburdened with work. From my very modest experience in this hospital I venture to present a case of a successful plastic operation on an upper lid and socket.

- Received for publication. June 21, 1946. 
The patient, Polish Lac. 1. P., wounded by a shell explosion in Italy had his eye enucleated on November 13, 1944, by Capt. R. H. Hughes, R.A.M.C., and was transferred to the 3rd Polish hospital in Italy, which sent him to the United Kingdom with the diagnosis "enucleated right eye, defect of lids, socket shrunk, evacuated to U.K. for plastic operation."

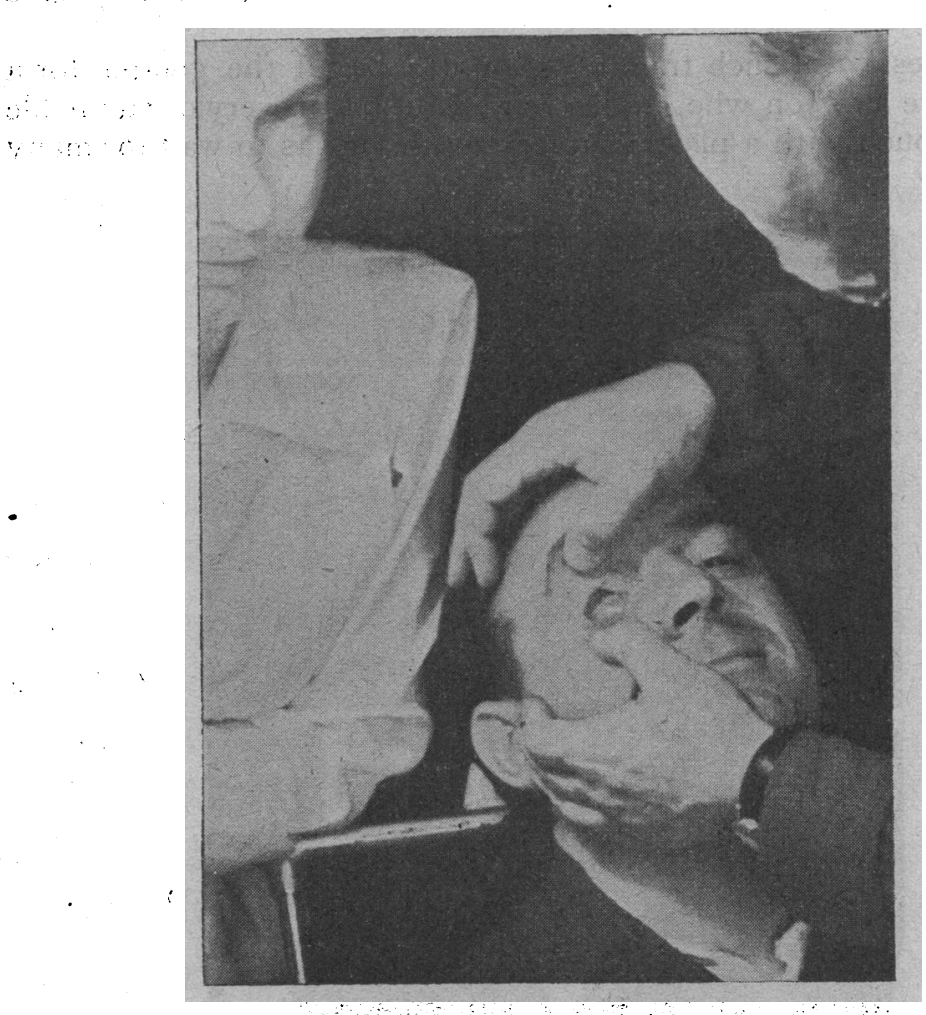

Fig. 2 .

The patient was seen in this country by Prof. Ballantyne at Killearn E.M.S. Hospital who advised his immediate transfer to a plastic unit.

The patient waited for a considerable time for admission to a plastic centre and finally, while the arrangements were still incomplete, was transferred to the 1st Polish Military Hospital.

When I saw him first his condition was as follows: The right upper lid showed a very large coloboma to such an extent that little more than a scarred and shrunken fragment of the lid was to be seen in the medial and outer canthus closely adhering to the socket. 
The socket in its upper portion was contracted, in the lower clean and healthy.

I decided to operate on him myself and as a first step to restore his upper lid. For this purpose the fragments of the lid in the region of both canthi were released and undermined, under local anaesthesia, in order to move them into position but it was impossible

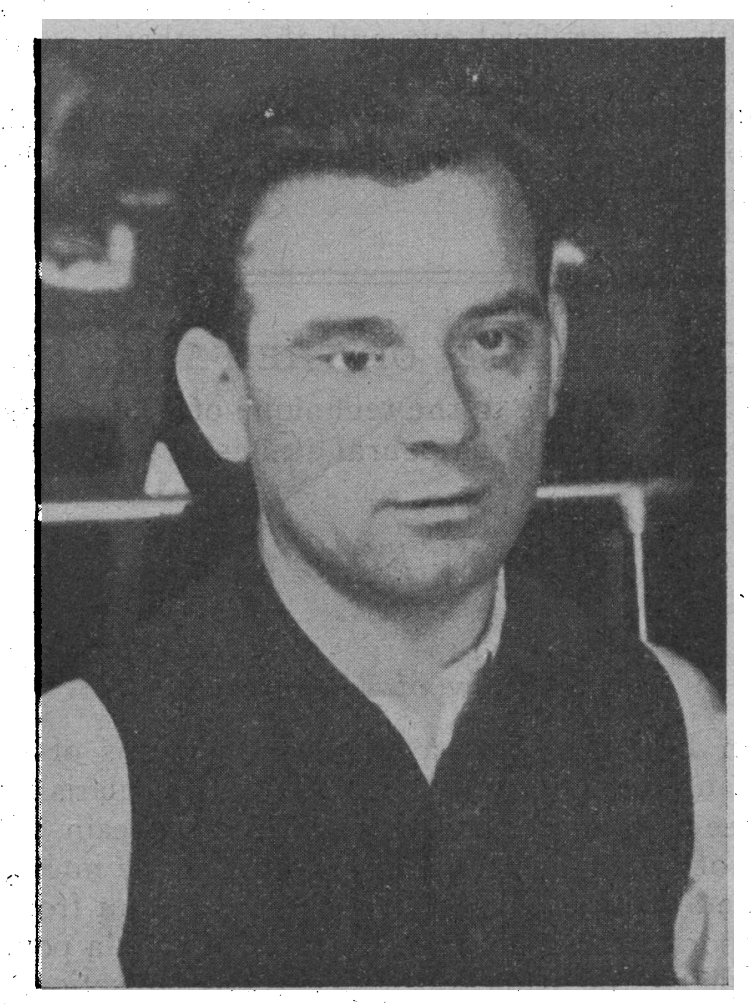

FIG. 3.

to sew the two parts together without tension, so a sliding graft from the skin of the temple was used. The result was very encouraging but the newly restored lid was closely attached to the socket. In order to enable the patient to be fitted with an artificial eye the nonexistent upper fornix had to be restored.

The operation was performed under infiltration anaesthesia following the modified Esser's method. From the inner surface of the right arm a free skin graft was taken because I judged a mucous membrane graft from the lip to be insufficient and too small for this purpose. An incision was made on the conjunctival side of what 
corresponded to the inner margin of the upper lid throughout its entire length. The skin was undermined to the required depth and an upper fornix formed. A piece of dentist's mould was then shaped so as to fit snugly into the pocket.

The graft was then folded over the inlay which was put into the cavity and the wound was closed with 4 sutures. After one week the stitches were removed and a shell eye fitted in.

There was hardly any appreciable shrinkage. The patient was provided with an artificial eye and the aesthetic result is fairly satisfactory.

I was unfortunately unable to have his photograph taken before the operations; the photographs, Figs. 1, 2 and 3 illustrate the result obtained.

\title{
SURGICAL ANATOMY OF THE FACIAL NERVE* With reference to the technique of orbicularis block (palpebral akinesia)
}

\author{
BY \\ M. KLEIN \\ LONDON

\section{Review of Literature}

IN 1914 van Lint described a method by means of which it is possible to cause temporary paralysis of the orbicularis muscle. He injected three or four c.c. of two per cent. novocain with two or three drops of adrenalin at a point situated at the intersection of a horizontal and vertical line, drawn $0.5 \mathrm{~cm}$. distant from the lower and the temporal margins of the orbit. Then from a point near the external angle of the palpebral fissure three injections are given directed away from the orbital margin towards the facial nerve, one c.c. being injected at each of three separate points, so as to cover all the branches supplying the orbicularis muscle. Fig. 1.

Similar procedures advocated by Villard in 1919 and Rochat in 1920 gained little support.

Modifications aiming at blocking the peripheral branches of the nerve were suggested by Rubbrecht in 1926, and Terson in 1931 . Rubbrecht advised the injections of 0.5 c.c. of 2 per cent. novocain each into the middle of the upper and lower lids, and of 0.5 c.c. near the external angle. The injections are directed towards the periosteum, and this method "makes akinesia unnecessary". Terson

\footnotetext{
${ }^{*}$ Received for publication, July 27, 1946
} 